\title{
Rate of Association of 2-Thenolytrifluoroacetone and Trioctylphosphine Oxide in Carbon Tetrachloride-Aqueous Solution Systems and Its Effect on the Solvent Extraction of Copper(II)
}

\author{
Akiko HokURA and Tatsuya Sekine \\ Department of Chemistry, Science University of Tokyo, \\ Kagurazaka, Shinjuku, Tokyo 162, Japan
}

\begin{abstract}
By spectrophotometry and by a liquid-liquid distribution method, the rate and equilibrium of the association of 2thenoyltrifluoroacetone (Htta) with trioctylphosphine oxide (TOPO) in carbon tetrachloride-aqueous $0.1 \mathrm{~mol} \mathrm{dm}^{-3}$ perchlorate solution systems were studied. The effect of this association on the rate and equilibrium of the solvent extraction of copper(II) in the liquid-liquid system containing these extractants was examined. The associate of these reagents in carbon tetrachloride at equilibrium was concluded to contain one TOPO, one water, and one keto form Htta molecule. The change in the distribution ratio of Htta during the two-phase agitation was larger in the presence of TOPO. The extraction of copper(II) from the aqueous phase with Htta in the presence of TOPO was higher just after the start of two-phase agitation and it decreased gradually until the equilibrium was reached. The rate of this decrease of copper(II) extraction was explained in terms of the rate of decrease in the Htta and TOPO concentrations due to their association in the organic phase.
\end{abstract}

Keywords Solvent extraction, 2-thenoyltrifluoroacetone, trioctylphosphine oxide, association, copper(II)

It is known that the solvent extraction of many kinds of metal ions with a $\beta$-diketone and a solvating type extractant such as tributylphosphate (TBP) or trioctylphosphine oxide (TOPO) is much better than that with each extractant. However, it is also known that such a synergistic effect is impaired by the association of the reagents in the organic phase, which is called an antagonistic effect. ${ }^{1}$ Recently, such associations have been studied more precisely. For example, we determined association constants of these two types of extractants from the change in the distribution ratio of the chelating reagent. ${ }^{2}$ It was pointed out by D'Olieslager and the coworkers that the $\beta$-diketone in such associates in the organic phase was in the hydrated form and that the associate contained one molecule of water together with one molecule of the $\beta$-diketone. ${ }^{3,4}$ The effect of association of the reagents on the solvent extraction of metal ions was examined for the extraction of alkaline earth ions with benzoyltrifluoroacetone (4,4,4-trifluoro-1phenyl-1,3-butanedione, Hbfa) and TOPO in carbon tetrachloride. $^{5}$ It was found that the distribution ratio of a $\beta$-diketone between carbon tetrachloride and the aqueous phase gradually lowered by the transformation of the enol form to the keto form in the aqueous phase. ${ }^{6}$ The rate of association of a $\beta$-diketone and a solvatingtype extractant was not high and thus the antagonistic effect appeared rather slowly. ${ }^{7}$ When copper(II) was extracted with mixtures of 2-thenoyltrifluoroacetone (4,4,4-trifluoro-1-(2-thienyl)-1,3-butanedione, Htta) and TOPO in carbon tetrachloride just after the preparation of the solvent, the distribution ratio was the highest in the initial stage and it gradually decreased during the twophase agitation until an equilibrium was reached. ${ }^{7}$

In the present paper, the rate and equilibrium of association of Htta and TOPO in carbon tetrachloride and that in liquid-liquid systems of this solvent and aqueous $0.1 \mathrm{~mol} \mathrm{dm}^{-3}$ perchlorate solutions were studied by measuring the change in the optical absorption of the solutions and the change in the distribution ratio of Htta in the systems. The change in the copper(II) extraction from the aqueous phase with Htta and TOPO into the organic phase was determined as a function of the twophase agitation time, this was considered from the standpoint of the rate of association of two reagents.

\section{Experimental}

All the experiments were made at $298 \mathrm{~K}$. All the reagents were analytical grade. The Htta and TOPO were obtained from Dojindo Laboratories. The carbon tetrachloride was washed three times with water. The 
Htta was purified by recrystallization from toluene and the TOPO was purified by recrystallization from cyclohexane. The stock solution of each reagent was prepared by dissolving the crystals in carbon tetrachloride. The sodium perchlorate was recrystallized three times from water. Deionized and distilled water was used. The stock solution of copper(II) was prepared by dissolving copper(Il) perchlorate in an acid aqueous perchlorate solution and the metal concentration was determined by an EDTA titration.

The optical absorption of sample solutions was measured by using quartz cells (light path $1 \mathrm{~cm}$ ) with a spectrophotometer (Hitachi U-3410).

The spectrophotometric measurements of $\mathrm{Htta}$ was made on the basis of the following assumptions.

Both the keto and enol form Htta in carbon tetrachloride solutions have absorptions in the UV range ${ }^{8,9}$, but since the absorption due to keto form is negligible above $350 \mathrm{~nm}$, only the amount of enol form should be obtained from the absorption at $355 \mathrm{~nm}$.

Both the keto and enol form $\mathrm{Htta}$ in aqueous solutions have absorptions in the UV range. ${ }^{8,9}$ The tautomeric equilibrium of the both forms should be established within a short time. ${ }^{9,10}$ Thus, when an aqueous solution of $\mathrm{Htta}$ is left standing longer than $30 \mathrm{~min}$, both forms should be in an equilibrium. This should be reasonable because the absorption spectrum of the solution did not change after $30 \mathrm{~min}$. From this, the calibration curve of the spectrophotometry was prepared by measuring standard aqueous $\mathrm{Htta}$ solutions which had been left standing for more than $30 \mathrm{~min}$ after the preparation. The total amount of $\mathrm{Htta}$ in aqueous sample solutions was also measured after they were left standing for more than $30 \mathrm{~min}$. The measurements were made at $267 \mathrm{~nm}$.

\section{Spectrophotometry of carbon tetrachloride solutions}

A portion of the stock solution of $\mathrm{Htta}$ and a portion of the stock solution of TOPO were mixed and transferred into a quartz cell. The optical absorption of the solution in the range from 300 to $400 \mathrm{~nm}$ was measured as a function of the standing time. The concentration of the enol form $\mathrm{Htta}$ in the solution was determined from the absorption at $355 \mathrm{~nm}$.

In order to determine the effect of water on the equilibrium and the rate of association of Htta and TOPO, carbon tetrachloride solutions of TOPO containing various amounts of water were prepared by mixing a water-saturated solution of TOPO and a solution of TOPO containing nearly no water. A portion of one of the Htta stock solutions was mixed with a portion of one of the TOPO solutions thus prepared. The water concentration was determined by a Karl-Fischer titration method.

\section{Measurements of partition of Htta}

The liquid-liquid partition experiments were made by using stoppered glass tubes (capacity $20 \mathrm{~cm}^{3}$ ). A portion of aqueous solution containing $0.010 \mathrm{~mol} \mathrm{dm}^{-3}$ of perchloric acid and $0.090 \mathrm{~mol} \mathrm{dm}^{-3}$ of sodium per- chlorate was placed in a tube and a portion of carbon tetrachloride solution of Htta and a portion of carbon tetrachloride solution of TOPO were added just before the start of two-phase agitation. The volume of aqueous and organic phase was the same. The two phases were vigorously agitated by a mechanical shaker or by hand for a certain time and then centrifuged off. The $\mathrm{Htta}$ in the aqueous phase was measured from the absorption at $267 \mathrm{~nm}$ after $30 \mathrm{~min}$ of the separation of the two phases. The total Htta concentration in the organic phase was obtained by subtracting the concentration in the aqueous phase from the initial concentration in the organic phase. The concentration of the enol form $\mathrm{Htta}$ in the organic phase was obtained by spectrophotometry.

An aqueous solution containing about $1 \times 10^{-4} \mathrm{~mol}$ $\mathrm{dm}^{-3} \mathrm{Htta}$ which was nearly only in the keto form was prepared by the method given in an earlier paper. ${ }^{9}$ It was agitated with the same volume of carbon tetrachloride containing $0.1 \mathrm{~mol} \mathrm{dm}^{-3}$ TOPO for $10 \mathrm{~s}$ and the extraction of Htta was measured from the absorption of the aqueous phase.

\section{Solvent extraction of copper(II)}

The experiments were made in a similar manner as described in the previous paper. ${ }^{7}$

\section{Statistical}

In the present paper, any chemical species in the organic phase is denoted by the subscript "org" and that in the aqueous phase by lack of any subscript. When the enol form $\mathrm{Htta}$ is denoted by $\mathrm{HE}$ and the sum of keto and keto hydrate form is denoted by $\mathrm{HK}$, the following relations can be written as long as the acid dissociation in the aqueous phase is negligible; 11

$$
\begin{aligned}
& {[\mathrm{Htta}]_{\text {org }}=[\mathrm{HE}]_{\text {org }}+[\mathrm{HK}]_{\text {org }}} \\
& {[\mathrm{Htta}]=[\mathrm{HE}]+[\mathrm{HK}]}
\end{aligned}
$$

In the organic solvents the enol form is dominant, and in the aqueous solutions the keto form is dominant. ${ }^{8,9}$

The association equilibrium of $\mathrm{Htta}$ and TOPO in the organic phase of the solvent extraction systems may be written as;

$$
\begin{aligned}
& \mathrm{Htta}_{\text {(org) }}+\mathrm{TOPO}_{\text {(org) }}^{*} \rightleftharpoons \mathrm{Htta} \cdot \mathrm{TOPO}_{\text {(org) }}^{*} \\
& K_{\mathrm{as}}{ }^{*}=\left[\mathrm{Htta} \cdot \mathrm{TOPO}^{*}\right]_{\mathrm{org}} /\left([\mathrm{Htta}]_{\mathrm{org}}[\mathrm{TOPO}]_{\mathrm{org}}\right)
\end{aligned}
$$

Here, TOPO ${ }_{\text {(org) }}^{*}$ represents both unhydrated TOPO and hydrated TOPO. Also, Htta·TOPO (org) represents all the associates of Htta with TOPO which are formed under the conditions. Since the organic phase of the solvent extraction systems is always saturated with water, the term of water is not written for the chemical species in the solvent extraction systems. This type of expression was employed in the previous paper from our laboratory. ${ }^{2}$ 
It was reported that, in an organic solvent, TOPO associated with water. ${ }^{12}$ The equilibrium was written as:

$$
\begin{aligned}
& \mathrm{TOPO}_{(\text {org) }}+\mathrm{H}_{2} \mathrm{O}_{\text {(org) }} \rightleftharpoons \mathrm{TOPO} \cdot \mathrm{H}_{2} \mathrm{O}_{\text {(org) }} \\
& K_{\text {as,w }}=\left[\mathrm{TOPO} \cdot \mathrm{H}_{2} \mathrm{O}\right]_{\text {org }} /\left([\mathrm{TOPO}]_{\mathrm{org}}\left[\mathrm{H}_{2} \mathrm{O}\right]_{\text {org }}\right)
\end{aligned}
$$

For the total amount of TOPO and $\mathrm{H}_{2} \mathrm{O}$ in an organic solvent, the following equations can be written:

$$
\begin{aligned}
& {[\mathrm{TOPO}]_{\text {org,total }}=} {[\mathrm{TOPO}]_{\mathrm{org}}+\left[\mathrm{TOPO} \cdot \mathrm{H}_{2} \mathrm{O}\right]_{\mathrm{org}} } \\
&+[\mathrm{Htta} \cdot \mathrm{TOPO}]_{\text {org }} \\
& {\left[\mathrm{H}_{2} \mathrm{O}\right]_{\text {org, otal }}=} {\left[\mathrm{H}_{2} \mathrm{O}\right]_{\mathrm{org}}+\left[\mathrm{TOPO} \cdot \mathrm{H}_{2} \mathrm{O}\right]_{\text {org }} } \\
&+[\mathrm{Htta} \cdot \mathrm{TOPO}]_{\text {org }}
\end{aligned}
$$

Since both [TOPO $]_{\text {org,total }}$ and $\left[\mathrm{H}_{2} \mathrm{O}\right]_{\text {org,total }}$ are in a large excess to [Htta] org.total under the conditions of the experiments with association of $\mathrm{Htta}$ and TOPO in carbon tetrachloride, the terms [Htta·TOPO* $]_{\text {org }}$ in Eqs. (4) and (5) should be negligible.

It should be possible to write general equations for the association of $\mathrm{Htta}$ and TOPO in an organic solution containing an amount of water. However, as it will be seen from the results, only the $\mathrm{Htta} \cdot \mathrm{H}_{2} \mathrm{O} \cdot \mathrm{TOPO}$ type of associate is formed. Thus, the following equations are written in the present paper in order to make the expressions simpler.

$\mathrm{Htta}_{\text {(org) }}+\mathrm{H}_{2} \mathrm{O}_{\text {(org) }}+\mathrm{TOPO}_{\text {(org) }} \rightleftharpoons \mathrm{Htta} \cdot \mathrm{H}_{2} \mathrm{O} \cdot \mathrm{TOPO}_{\text {(org) }}$ $K_{\text {as }}=\left[\mathrm{Htta} \cdot \mathrm{H}_{2} \mathrm{O} \cdot \mathrm{TOPO}\right]_{\text {org }} /\left([\mathrm{Htta}]_{\text {org }}\left[\mathrm{H}_{2} \mathrm{O}\right]_{\text {org }}[\mathrm{TOPO}]_{\text {org }}\right)$

The distribution ratio of Htta is written as

$$
\begin{aligned}
D_{\mathrm{Htta}} & =[\mathrm{Htta}]_{\mathrm{org}} /[\mathrm{Htta}] \\
& =\left([\mathrm{HE}]_{\text {org }}+[\mathrm{HK}]_{\mathrm{org}} /([\mathrm{HE}]+[\mathrm{HK}])\right.
\end{aligned}
$$

The value of this $D_{\text {Htta }}$ should be identical to the distribution constant which is usually written as $K_{\mathrm{d}}=[\mathrm{Htta}]_{\text {org }} /$ [Htta].

The distribution ratio of TOPO is very high and, consequently, TOPO and its associates in the aqueous phase should be negligible. Thus, the following equation can be written:

$$
\begin{aligned}
D_{\mathrm{Htta}}= & \left([\mathrm{Htta}]_{\mathrm{org}}+\left[\mathrm{Htta} \cdot \mathrm{H}_{2} \mathrm{O} \cdot \mathrm{TOPO}\right]_{\mathrm{org}} /[\mathrm{Htta}]\right. \\
= & \left([\mathrm{HE}]_{\mathrm{org}}+[\mathrm{HK}]_{\mathrm{org}}+\left[\mathrm{Htta} \cdot \mathrm{H}_{2} \mathrm{O} \cdot \mathrm{TOPO}\right]_{\mathrm{org}}\right) \\
& /([\mathrm{HE}]+[\mathrm{HK}])
\end{aligned}
$$

When the equilibrium is established, it can also be written as

$$
D_{\text {Htta }}=K_{\mathrm{d}}\left(1+K_{\text {as }}\left[\mathrm{H}_{2} \mathrm{O}\right]_{\mathrm{org}}[\mathrm{TOPO}]_{\mathrm{org}}\right)
$$

The solvent extraction of copper(II) with Htta may be written as

$$
\begin{aligned}
& \mathrm{Cu}^{2+}+2 \mathrm{Htta}_{\text {(org) }} \rightleftharpoons \mathrm{Cu}(\mathrm{tta})_{2(\mathrm{org})}+2 \mathrm{H}^{+} \\
& K_{\mathrm{ex}}=\left(\left[\mathrm{Cu}\left(\mathrm{tta}_{2}\right]_{\mathrm{org}_{\mathrm{g}}}\left[\mathrm{H}^{+}\right]^{2}\right) /\left(\left[\mathrm{Cu}^{2+}\right][\mathrm{Htta}]_{\mathrm{org}_{\mathrm{g}}}\right)\right.
\end{aligned}
$$

The association of $\mathrm{Cu}(\mathrm{tta})_{2}$ and TOPO in the organic phase may be written as ${ }^{7}$

$$
\begin{aligned}
& \mathrm{Cu}(\mathrm{tta})_{2 \text { (org) }}+\mathrm{TOPO}_{\text {(org) }} \rightleftharpoons \mathrm{Cu}(\mathrm{tta})_{2} \mathrm{TOPO}_{\text {(org) }} \\
& \beta_{\text {(org) }}=\left[\mathrm{Cu}(\mathrm{tta})_{2} \mathrm{TOPO}_{\text {org }} /\left(\left[\mathrm{Cu}(\mathrm{tta})_{2}\right]_{\text {org }}[\mathrm{TOPO}]_{\text {org }}\right)\right.
\end{aligned}
$$

When no formation of copper(II) chelate in the aqueous phase is assumed, the distribution ratio is written as ${ }^{13}$

$$
D_{0}=\left[\mathrm{Cu}(\mathrm{tta})_{2}\right]_{\mathrm{org}} /\left[\mathrm{Cu}^{2+}\right]=K_{\mathrm{ex}}[\mathrm{Htta}]_{\mathrm{org}^{2}} /\left[\mathrm{H}^{+}\right]^{2}
$$

When TOPO is present and the adduct chelate containing one TOPO is formed, the distribution ratio, $D_{t}$, after a certain duration of the two-phase agitation, $t$, can be written as?

$$
\begin{aligned}
D_{\mathrm{t}} & =\left(\left[\mathrm{Cu}(\mathrm{tta})_{2}\right]_{\text {org }}+\mathrm{Cu}(\mathrm{tta})_{2} \mathrm{TOPO}\right]_{\mathrm{org}} /\left[\mathrm{Cu}^{2+}\right] \\
& =K_{\text {ex }}[\mathrm{Htta}]_{\text {org, },}{ }^{2}\left(1+\beta_{(\mathrm{org}) 1}[\mathrm{TOPO}]_{\text {org },}\right) /\left[\mathrm{H}^{+}\right]^{2}
\end{aligned}
$$

where $[\mathrm{Htta}]_{\text {org, }}$ is the concentration of $\mathrm{Htta}$ in the organic phase after $t$, which can be obtained by spectrometry and [TOPO] $]_{\text {org, }}$ is the concentration of TOPO in the organic phase after $t$, which can be obtained from [Htta] $]_{\text {org,t }}$ on the basis of Eqs. (3) to (6).

The statistical treatment of the rate of reactions will be written in the section of results.

\section{Results}

\section{Spectrophotometry of carbon tetrachloride solutions}

An organic solution of $\mathrm{Htta}$ absorbs in the UV region. ${ }^{8}$ The molar extinction coefficient of $\mathrm{Htta}$ in carbon tetrachloride at $355 \mathrm{~nm}$ was found to be $1.10 \times 10^{4}$ $\mathrm{mol}^{-1} \mathrm{dm}^{3} \mathrm{~cm}^{-1}$. This is due to the absorption by the enol form Htta; the absorption by the keto form is negligible at this wavelength. ${ }^{9}$ It was also found that the absorption of carbon tetrachloride solution of TOPO at this wavelength was negligible.

The absorption of Htta solution was found to be constant in the absence of TOPO for one week. On the other hand, when an Htta solution was combined with a portion of TOPO solution, the absorption in the wavelength range from 300 to $400 \mathrm{~nm}$ decreased gradually due to the decrease in the enol form until an equilibrium was reached. The decrease was determined as a function of the standing time when the solution contained $1 \times 10^{-4} \mathrm{~mol} \mathrm{dm}^{-3} \mathrm{Htta}$, various amounts of TOPO, and was saturated by water. The decrease in the absorption was also measured when the solution 
Table 1 Association constant in carbon tetrachloride in Eq. (6) at various water concentrations

\begin{tabular}{ccccc}
\hline $\log [\mathrm{Htta}]_{\text {org }}$ & $\log \left[\mathrm{H}_{2} \mathrm{O}\right]_{\text {org }}$ & $\log [\mathrm{TOPO}]_{\text {org }}$ & $\log \left[\mathrm{Htta} \cdot \mathrm{H}_{2} \mathrm{O} \cdot \mathrm{TOPO}\right]_{\text {org }}$ & $\log K_{\text {as }}$ \\
\hline-3.98 & -3.13 & -1.07 & -4.89 & 3.29 \\
-4.01 & -2.93 & -1.08 & -4.70 & 3.33 \\
-4.05 & -2.79 & -1.10 & -4.54 & 3.40 \\
-4.07 & -2.64 & -1.12 & -4.49 & 3.33 \\
-4.15 & -2.38 & -1.17 & -4.33 & 3.38 \\
-4.27 & -2.24 & -1.21 & -4.27 & 3.45 \\
-4.17 & -2.12 & -1.25 & -4.30 & 3.24 \\
-4.21 & -2.00 & -1.30 & -4.25 & 3.26 \\
\hline
\end{tabular}

The total Htta concentration is $1 \times 10^{-4} \mathrm{~mol} \mathrm{dm}^{-3}$ and the total TOPO concentration is $9.0 \times 10^{-2} \mathrm{~mol} \mathrm{dm}^{-3}$. The [Htta $]_{\text {org }}$ was calculated from the absorption at $355 \mathrm{~nm}$ and the $\left[\mathrm{Htta} \cdot \mathrm{H}_{2} \mathrm{O} \cdot \mathrm{TOPO}\right]_{\text {org }}$ was calculated from the relation: $\left[\mathrm{Htta} \cdot \mathrm{H}_{2} \mathrm{O} \cdot \mathrm{TOPO}\right]_{\text {org }}=[\mathrm{Htta}]_{\text {org.total }}-[\mathrm{Htta}]_{\text {org. }}$ The $[\mathrm{TOPO}]_{\text {org }}$ and $\left[\mathrm{H}_{2} \mathrm{O}\right]_{\text {orgwere }}$ calculated from Eqs. (3) to (5).

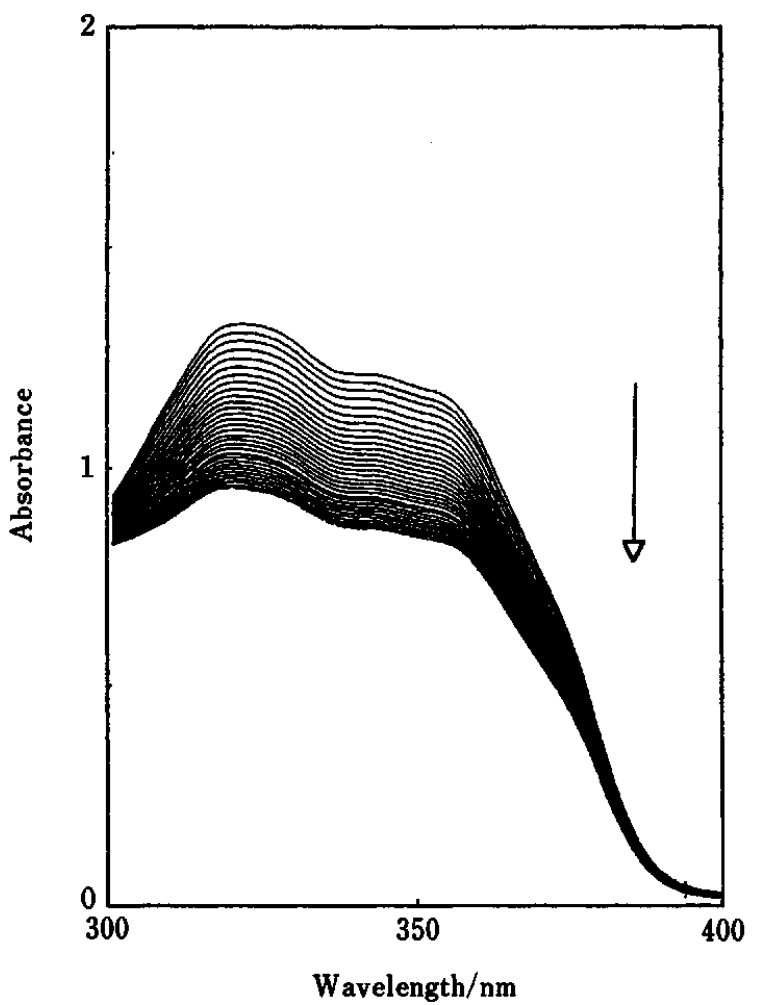

Fig. 1 Change in the absorption spectrum of carbon tetrachloride solution containing Htta when TOPO was added as a function of standing time. The initial concentration of $\mathrm{Htta}$ was $1 \times 10^{-4} \mathrm{~mol} \mathrm{dm}^{-3}$ and that of TOPO was $8.0 \times 10^{-2}$ $\mathrm{mol} \mathrm{dm}{ }^{-3}$. The total water concentration was determined to be $5 \times 10^{-3} \mathrm{~mol} \mathrm{dm}^{-3}$ by the Karl-Fischer titration method. The standing time was $1 \mathrm{~min}$ (the top) to $300 \mathrm{~min}$ (the bottom) and the measurements were made every $10 \mathrm{~min}$.

contained $1 \times 10^{-4} \mathrm{~mol} \mathrm{dm}^{-3} \quad \mathrm{Htta}, 9.0 \times 10^{-2} \mathrm{~mol} \mathrm{dm}^{-3}$ TOPO, and various amounts of water. Figure 1 gives an example of the change in the absorption. From the absorption after $24 \mathrm{~h}$ of the mixing of solutions, the association constant in Eq. (6) was calculated. The values of association constant thus obtained from the sample solutions containing various amounts of water are given in Table 1. The association constant, $K_{\mathrm{as}}{ }^{*}$, in Eq. (2), which was obtained when the solvent was saturated with water ${ }^{2}$, was recalculated on the basis of Eqs. (3) and (6). The value of $K_{\text {as }}$ in Eq. (6) thus obtained was $10^{3.45}$. This value agrees with the value experimentally obtained in the present study in Table 1, 103.34. From these, the associate of Htta and TOPO was concluded to contain one water molecule as was reported about the associates of benzoyltrifluoroacetone with $\mathrm{TBP}^{3}$ or with triphenylphosphine oxide in benzene. ${ }^{4}$

When TOPO and water are in a large excess to Htta and the dissociation of the associate is negligible, the kinetic data can be treated by the following equation:

$$
v=-\mathrm{d}[\mathrm{HE}]_{\mathrm{org}} / \mathrm{d} t=k[\mathrm{HE}]_{\mathrm{org}}[\mathrm{TOPO}]_{\mathrm{org}} \mathrm{a}_{2}\left[\mathrm{H}_{2} \mathrm{O}\right]_{\mathrm{org}} \mathrm{b} \ldots
$$

$$
\log \left([\mathrm{HE}]_{\mathrm{org}} /[\mathrm{HE}]_{\mathrm{org}, \mathrm{ini}}\right)=-\left(k_{\mathrm{obso}} / 2.303\right) t
$$

where

$$
k_{\text {obsd }}=k[\mathrm{TOPO}]_{\mathrm{org}^{\mathrm{a}}}\left[\mathrm{H}_{2} \mathrm{O}\right]_{\mathrm{org}}{ }^{\mathrm{b}} \ldots
$$

From the change in the absorption of the sample solution containing Htta and TOPO, the $\log \left([\mathrm{HE}]_{\text {org }} /\right.$ $\left.[H E]_{\text {org, init }}\right) v s . t$ plot was made. The plot was a straight line in the early stage after the mixing of the two reagents but it changed gradually until the equilibrium was reached. On the basis of Eq. (15), the value of $k_{\text {obsd }}$ was obtained from the slope of the plot in the early stage, within $20 \mathrm{~min}$ of the start. Figure 2(a) gives the dependence of the $k_{\text {obsd }}$ on the total TOPO concentration when the solvent was saturated with water and contained $1 \times$ $10^{-4} \mathrm{~mol} \mathrm{dm}^{-3} \mathrm{Htta}$. As is seen from Fig. 2(a), the observed rate constant is first order with respect to the total TOPO. Figure 2(b) gives the dependence of the $k_{\mathrm{obsd}}$ on the total water concentration when the total TOPO concentration was $0.09 \mathrm{~mol} \mathrm{dm}^{-3}$ and the total Htta concentration was $1 \times 10^{-4} \mathrm{~mol} \mathrm{dm}^{-3}$. As is seen from Fig. 2(b), the observed rate constant is first order with respect to the 


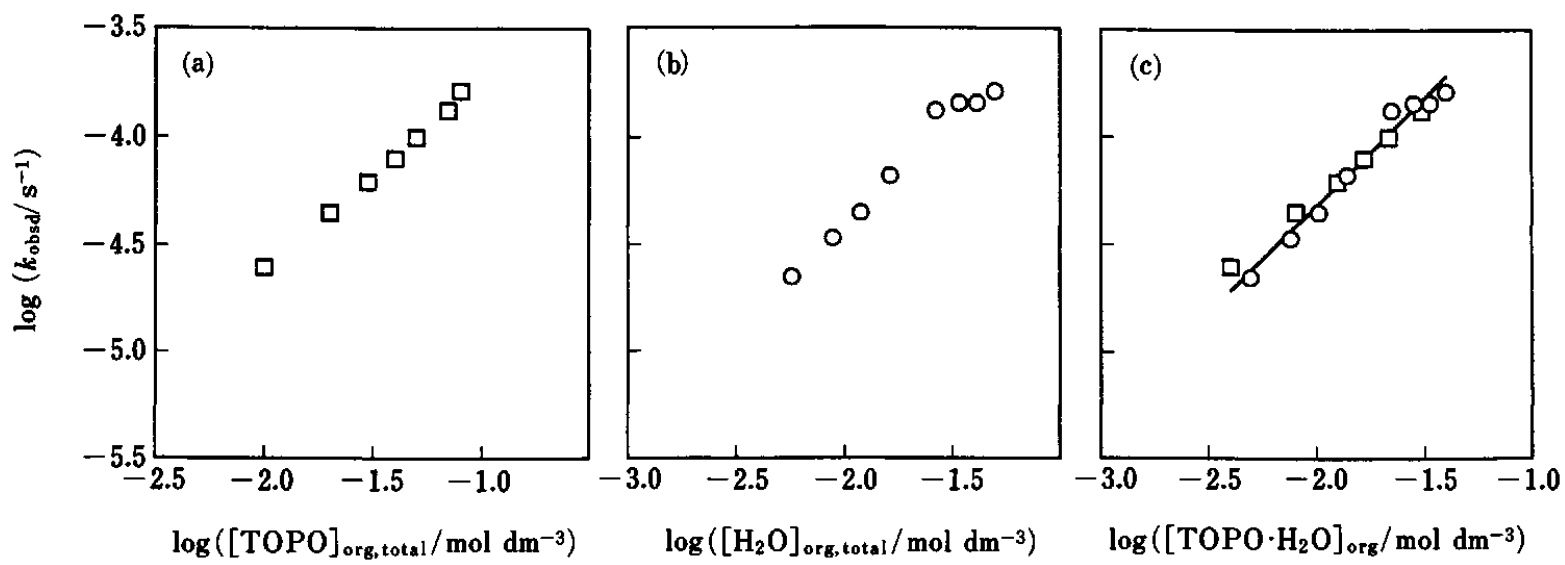

Fig. 2 Dependence of the observed rate constant in Eq. (15) for the association of Htta and TOPO in carbon tetrachloride solution on the basis of Eq. (16). The total $\mathrm{Htta}$ concentration was $1 \times 10^{-4} \mathrm{~mol}$ $\mathrm{dm}^{-3}$. (a) As a function of the total TOPO concentration when carbon tetrachloride was saturated with water. (b) As a function of total water concentration when carbon tetrachloride contained $9 \times 10^{-2} \mathrm{~mol} \mathrm{dm}^{-3}$ of total TOPO. (c) The observed rate constant as a function of the TOPO $\cdot \mathrm{H}_{2} \mathrm{O}$ concentration calculated by using Eq. (3).

total water concentration.

\section{Liquid-liquid partition of Htta}

A carbon tetrachloride solution containing $1 \times 10^{-3}$ mol dm$~^{-3}$ Htta was agitated with the acid aqueous perchlorate solution. The amount of Htta in the aqueous phase was determined from the absorption at $267 \mathrm{~nm}$ where the molar extinction coefficient was $1.08 \times 10^{4}$ $\mathrm{mol}^{-1} \mathrm{dm}^{3} \mathrm{~cm}^{-1}$. The distribution ratio of $\mathrm{Htta}$ in the absence of TOPO was measured as a function of the time of two-phase agitation. The results are given by squares in Fig. 3. As is seen from Fig. 3, the distribution ratio was about $1.0 \times 10^{2}$ after the two-phase agitation for $5 \mathrm{~s}$; then it decreased gradually until the distribution equilibrium was established after about $60 \mathrm{~min}$.

Figure 3 also gives the distribution ratio of $\mathrm{Htta}$ in the presence of TOPO as a function of the time of two-phase agitation. The solution of Htta and that of TOPO were mixed just before the start of two-phase agitation. The distribution ratio of Htta in the initial stage was dependent on the TOPO concentration. The distribution ratio decreased during the two-phase agitation until the equilibrium was reached after $60 \mathrm{~min}$. The distribution ratio at equilibrium, after $60 \mathrm{~min}$ of the start of two-phase agitation, agrees well with the calculated values on the basis of Eq. (9), to which are introduced the values $K_{\mathrm{d}}=2.2 \times 10$ (ref. 9) and $K_{\mathrm{as}}=10^{3.34}$ as they are given in the figure caption.

The aqueous solution containing about $1 \times 10^{-4} \mathrm{~mol}$ $\mathrm{dm}^{-3} \mathrm{Htta}$ which was approximately only the keto form was agitated with carbon tetrachloride containing $0.1 \mathrm{~mol} \mathrm{dm}^{-3}$ TOPO. The keto form $\mathrm{Htta}$ in the aqueous phase was nearly quantitatively extracted $\left(D_{\mathrm{Htta}}\right.$ in Eq. (8) was higher than $10^{2.5}$ ) during the two-phase agitation for such a short time as $10 \mathrm{~s}$. Thus, the association of the keto form Htta and TOPO in the

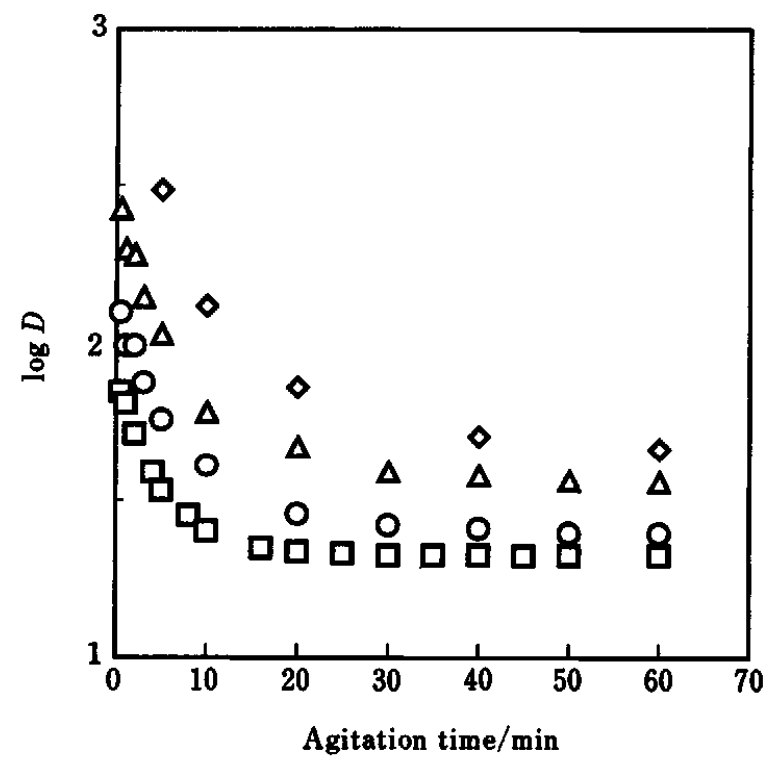

Fig. 3 Distribution ratio of Htta as a function of two-phase agitation time. Organic phase: carbon tetrachloride containing Htta which was left standing for one day and it was added to TOPO just before the two-phase agitation. It initially contained $1.0 \times 10^{-3} \mathrm{~mol} \mathrm{dm}^{-3} \mathrm{Htta}$ and 0 (口), $1.0 \times 10^{-2}(O), 5 \times 10^{-2}(\triangle)$, or $8 \times 10^{-2}(\diamond) \mathrm{mol} \mathrm{dm}^{-3}$ TOPO. Aqueous phase: perchlorate solution containing $1.0 \times 10^{-2}$ mol dm$~_{-3} \mathrm{HClO}_{4}$ and $9 \times 10^{-2} \mathrm{~mol} \mathrm{dm}^{-3} \mathrm{NaClO}_{4}$. The value of $\diamond$ in the earliest stage is not given because it is too high to be measured. The values of $D_{\text {Htta }}$ at equilibrium were calculated on the basis of Eq. (9) to be $10^{1.39}(O), 10^{1.54}(\triangle)$, and $10^{1.63}(\diamond)$.

carbon tetrachloride solution should proceed very rapidly and the equilibrium is very favorable for the association when TOPO is in a large excess to the keto 

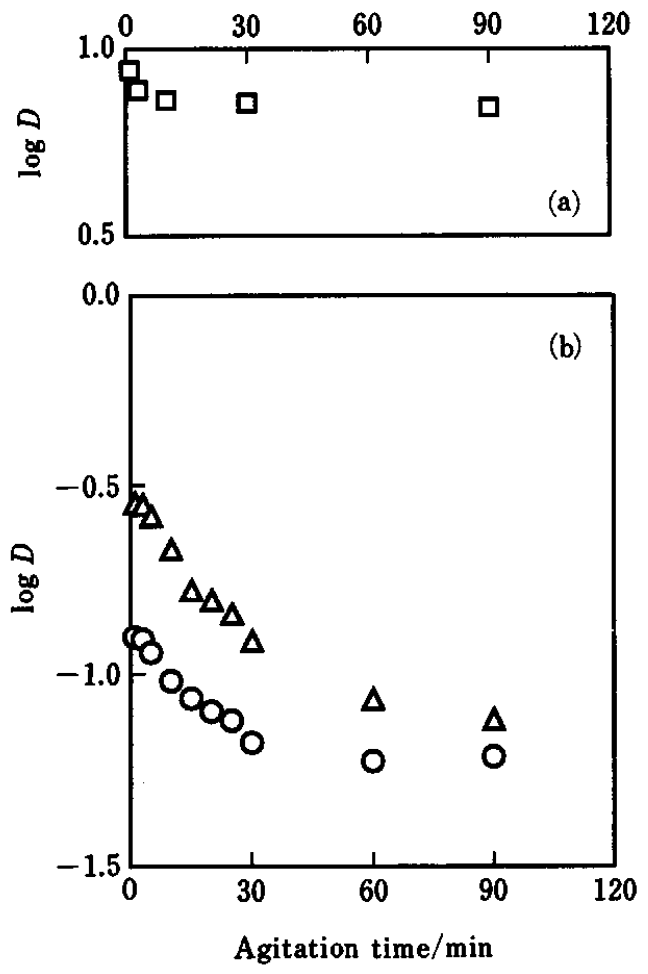

Fig. 4 The change in the distribution ratio of copper(II) as a function of the agitation time. Organic phase is carbon tetrachloride (a) initially containing $1.0 \times 10^{-1} \mathrm{~mol} \mathrm{dm}^{-3} \mathrm{Htta}$ (口), (b) initially containing $1.0 \times 10^{-3} \mathrm{~mol} \mathrm{dm}^{-3} \mathrm{Htta}$ and $5 \times 10^{-2}(O)$ or $1.0 \times 10^{-1}(\triangle) \mathrm{mol} \mathrm{dm}^{-3}$ TOPO. Aqueous phase initially contains $2 \times 10^{-5} \mathrm{~mol} \mathrm{dm}^{-3} \mathrm{Cu}^{2+}, 1.0 \times 10^{-2}$ mol dm ${ }^{-3} \mathrm{HClO}_{4}$, and $9 \times 10^{-2} \mathrm{~mol} \mathrm{dm}^{-3} \mathrm{NaClO}_{4}$.

form Htta.

\section{Solvent extraction of copper(II)}

The solvent extraction of copper(II) in the absence and presence of TOPO was determined as a function of the time of two-phase agitation. The results are given in Fig. 4. The distribution ratio was the highest in the earliest stage (after $60 \mathrm{~s}$ of the start of two-phase agitation). In the absence of TOPO, only the $\mathrm{Cu}(\mathrm{tta})_{2}$ should be extracted, but in the presence of TOPO both $\mathrm{Cu}(\mathrm{tta})_{2}$ and $\mathrm{Cu}(\mathrm{tta})_{2}$ (TOPO) should be extracted. ${ }^{7,13}$

When the initial concentration of $\mathrm{Htta}$ in the organic phase is $0.1 \mathrm{~mol} \mathrm{dm}^{-3}$ in the absence of TOPO, the distribution ratio of copper(II) is $10^{0.94}$ after the twophase agitation for $60 \mathrm{~s}$, as is seen from the squares in Fig. 4(a). The distribution ratio decreased a little until the equilibrium was reached where the distribution ratio was $10^{0.84}$.

As is seen from Fig. 4(b), the distribution ratio decreased gradually in the presence of TOPO while the twophase agitation was continued and the decrease was greater when the TOPO concentration was higher.

\section{Discussion}

As was described in the previous paper ${ }^{9}$, the two-phase distribution of $\mathrm{Htta}$ in the liquid-liquid system was not a rapid reaction either when the $\beta$-diketone was initially added into the organic phase or into the aqueous phase: it took about $90 \mathrm{~min}$ until the equilibrium was established. As is seen from Fig. 3, the time to reach the liquid-liquid distribution equilibrium of $\mathrm{Htta}$ is a little longer when TOPO is added than when it is not added. The change in the absorption spectrum of the carbon tetrachloride solution containing both Htta and TOPO and being in contact with no aqueous solution is also slow, as is seen from Fig. 1: even after $3 \times 10^{2} \mathrm{~min}$, the absorbance is decreasing. This is much slower than the two-phase distribution reaction of Htta which is initially added to carbon tetrachloride solution containing TOPO. The association of Htta and TOPO in the organic phase should be in an equilibrium when the distribution reaction of $\mathrm{Htta}$ in the liquid-liquid system is in the equilibrium. Thus the association reaction should proceed more rapidly in the organic phase in the liquid-liquid system than in the carbon tetrachloride solution which is not in contact with any aqueous solution.

This can be explained as follows. In a carbon tetrachloride solution, the enolization and ketonization are much slower than those in an aqueous solution. When the organic phase containing $\mathrm{Htta}$ and TOPO is agitated with an aqueous phase, a part of the enol form of Htta transferred into the aqueous phase and it changes to the keto form much more rapidly than in the organic phase. At the same time, a part of the keto form Htta thus formed in the aqueous phase is extracted into the organic phase. The association of the keto form of $\mathrm{Htta}$ with TOPO in the organic phase containing water is very rapid, as was found experimentally. Thus, the association of Htta with TOPO in the organic phase containing water should proceed through two routes. One is the association of enol form with TOPO in the organic phase and its change to the keto form. The other is the ketonization of enol form Htta in the aqueous phase which transferred from the organic phase and the extraction of thus-formed keto form into the organic phase and then its association with TOPO. The reaction through the latter route is much faster than that through the former route because of the very fast ketonization in the aqueous phase. For this reason, the association of Htta and TOPO in the liquid-liquid system proceeds more quickly than the association in a single carbon tetrachloride solution system.

Since the absorbance of carbon tetrachloride solutions at $355 \mathrm{~nm}$ due to the enol form Htta was constant in the absence of TOPO, but it decreased by an addition of TOPO, and since the keto form Htta had only negligible absorption at this wavelength, the decrease in the absorbance should be due to the decrease in the concentration of enol form Htta. The absence of change in the 
absorption in the absence of TOPO should be due to the fact that the keto and enol form $\mathrm{Htta}$ were in an equilibrium. It is known that about $99 \%$ of the total Htta should be in the enol form and $1 \%$ should be in the keto form in a solution at equilibrium. ${ }^{9}$ When TOPO was added into the carbon tetrachloride solution of $\mathbf{H t t a}$, the keto form should associate with the TOPO very rapidly, as was found in the present study.

In the present study, it was not possible to distinguish the unhydrated keto form from the hydrated keto form of Htta. However, it should be reasonable to assume that the absorption of both types of keto form is negligible at $355 \mathrm{~nm}$ where the enol form is determined by spectrophotometry. It would also be possible that the rate of change between these two keto forms and the rate of association of these two forms with TOPO in the presence of water could be very high. However, these can not be determined by the experimental method in the present study.

As is seen from Fig. 2(a) and 2(b), the rate of decrease in the concentration of enol form is dependent on both the TOPO and water. The observed rate constant of ketonization in water-saturated carbon tetrachloride was $10^{-7.0} \mathrm{~s}^{-1}$, as was given in ref. 9. This is more than two orders lower than the values of $k_{\text {obsd }}$ in Fig. 2(a) and 2(b). Such a rapid decrease of the enol form occurs in the presence of both TOPO and water. Since the association of TOPO and water should proceed very rapidly, the first order dependence of the rate of decrease of the enol form Htta on both TOPO and water indicates that the reaction should occur by the association of the enol form Htta and hydrated TOPO. The chemical form of Htta in this associate can not be assumed from this disappearance of the absorption at $355 \mathrm{~nm}$ by the formation of the associate. However, the Htta in the associate should be in the keto form which has no absorption in this wavelength range. At the same time, the rapid extraction of the keto form Htta with TOPO should also support this assumption.

The reasonable explanation for this should be that the enol form Htta associates with hydrated TOPO and this enol form Htta in this associate changes to the keto form. The change should cause the decrease of the absorption due to the enol form Htta. From this, it should be concluded that the associate consists of one TOPO, one water molecule, and one keto form Htta molecule.

However, when TOPO was added to a carbon tetrachloride solution of $\mathrm{Htta}$, no observation which indicated the formation of associate of $\mathrm{HE}$ with TOPO $\cdot \mathrm{H}_{2} \mathrm{O}$ was found. This should be due to the fact that the spectrum of the intermediate, the associate of $\mathrm{HE}$ with TOPO. $\mathrm{H}_{2} \mathrm{O}$, was not very much different from that of free $\mathrm{HE}$, or that the amount of the associate of HE with TOPO. $\mathrm{H}_{2} \mathrm{O}$ was too small to observe from the change in the spectrum of the solution. For this reason, the rate of ketonization of the enol form $\mathrm{Htta}$ in the associate could not be estimated. However, it should be reasonable to assume that the rate is much higher than the ketonization of $\mathrm{HE}$ in carbon tetrachloride which is not associated with TOPO.

The association equilibrium of TOPO and water in carbon tetrachloride can be written by Eq. (3) and the value of $K_{\text {as, w }}$ was calculated from the literature value ${ }^{12}$ to be $7.9 \times 10$. From this value and from the concentration of water in water-saturated carbon tetrachloride which is $0.01 \mathrm{~mol} \mathrm{dm}^{-3}$, it is calculated that $44 \%$ of TOPO is in the hydrated form, TOPO $\cdot \mathrm{H}_{2} \mathrm{O}$, under the conditions of the experiments in Fig. 2(a). As long as the solvent is saturated with water, this percentage of the TOPO $\cdot \mathrm{H}_{2} \mathrm{O}$ species should not be affected by the total TOPO concentration. For this reason, when the values of rate constant given in Fig. 2(a) and 2(b) are plotted against the calculated values of $\log \left[\mathrm{TOPO} \cdot \mathrm{H}_{2} \mathrm{O}\right]_{\text {org }}$, a straight line of slope +1 should be obtained. Figure $2(\mathrm{c})$ gives this plot. Thus it can be concluded that the controlling reaction should be the change of the enol form in the associate with TOPO $\cdot \mathrm{H}_{2} \mathrm{O}$ and by this reaction, the associate of a TOPO, a water and a keto form Htta molecule is formed. The observed rate constant can be written as:

$$
k_{\mathrm{obsd}}=k^{\prime}\left[\mathrm{TOPO} \cdot \mathrm{H}_{2} \mathrm{O}\right]_{\mathrm{org}}
$$

where $k^{\prime}=k K_{\mathrm{as}, \mathrm{w}}{ }^{-1}$ as is seen from Eqs. (3), (15), and (16). From the results in Fig. 2(c), the value of $k^{\prime}$ is obtained to be $10^{-2.3} \mathrm{~mol}^{-1} \mathrm{dm}^{3} \mathrm{~s}^{-1}$.

The distribution ratio of $\mathrm{Htta}$ is higher in the presence of TOPO. Since most of Htta in the water-saturated carbon tetrachloride should be in the enol form, the higher distribution ratio of Htta in the presence of TOPO should be due to the formation of associate of a keto form $\mathrm{Htta}$ and a TOPO $\cdot \mathrm{H}_{2} \mathrm{O}$, as is written with the association in carbon tetrachloride which is not in contact with water. The keto form is present in the aqueous phase even in the earliest stage because of the quick ketonization in the aqueous phase, as was experimentally confirmed. ${ }^{9,10}$ The keto form in the aqueous phase is extracted with TOPO into the organic phase very rapidly as long as the TOPO is in a large excess to the keto form Htta.

As was already described in the previous paper, the extraction of indium(III) with Htta was not very much affected by the two-phase agitation time. ${ }^{9}$ The same is observed with the copper(II) extraction with Htta in the absence of TOPO, as is seen from the squares in Fig. 4(a): the difference of distribution ratio after the two-phase agitation for $1 \mathrm{~min}$ to $60 \mathrm{~min}$ is $10^{0.1}$. This agrees with the change in the Htta concentration in the organic phase. On the other hand, the difference is much larger in the presence of TOPO where the association of Htta and TOPO occurs. The "free" Htta in the organic phase which was predominantly in the enol form and thus available for the metal chelate extraction, and the "free" TOPO which is available for the adduct chelate formation could not be calculated from the kinetic data by using only Eq. (15) and the value of experimentally obtained $k_{\text {obsd. }}$. Thus, the free Htta in the organic phase after a certain time from the start of two-phase agitation 
Table 2 The change in the distribution ratio of copper(II) as a function of the two-phase agitation time experimentally obtained and calculated by using both concentrations of $\mathrm{Htta}$ and TOPO on the basis of Eq. (13)

\begin{tabular}{|c|c|c|c|c|}
\hline \multirow[b]{2}{*}{ Agitation time/min } & \multicolumn{2}{|c|}{$0.05 \mathrm{M}$ TOPO } & \multicolumn{2}{|c|}{$0.1 \mathrm{M}$ ТОРО } \\
\hline & $\begin{array}{l}\text { Experimental } \\
\log \left(D_{\mathrm{t}} / D_{\mathrm{lmin}}\right)\end{array}$ & $\begin{array}{c}\text { Calculated } \\
\log \left(D_{\mathrm{t}} / D_{\mathrm{t} \text { min }}\right)\end{array}$ & $\begin{array}{l}\text { Experimental } \\
\log \left(D_{\mathrm{t}} / D_{1 \text { min }}\right)\end{array}$ & $\begin{array}{c}\text { Calculated } \\
\log \left(D_{\mathrm{t}} / \mathbf{D}_{1 \mathrm{~min}}\right)\end{array}$ \\
\hline 1 & 0 & 0 & 0 & 0 \\
\hline 3 & -0.02 & -0.01 & -0.03 & -0.01 \\
\hline 5 & -0.05 & -0.04 & -0.05 & -0.03 \\
\hline 10 & -0.14 & -0.11 & -0.17 & -0.12 \\
\hline 20 & -0.22 & -0.19 & -0.29 & -0.26 \\
\hline 30 & -0.28 & -0.27 & -0.39 & -0.37 \\
\hline 60 & -0.33 & -0.32 & -0.52 & -0.52 \\
\hline 90 & -0.34 & -0.31 & -0.57 & -0.57 \\
\hline
\end{tabular}

$D_{1 \text { min }}$ is distribution ratio of copper(II) after the two-phase agitation for 1 min and $D_{\mathrm{t}}$ is that after the two-phase agitation for the given time. Here, $K_{\mathrm{ex}}$ in Eq. (10) is $10^{-1.1}$ (ref. 13) and $\beta_{(\mathrm{org}) !}$ in Eq. (11) is $10^{3.6}$ (ref. 7 ).

was determined from the absorption at $355 \mathrm{~nm}$. From the decrease in the absorption, the amount of Htta associated with TOPO was calculated and the amount of free TOPO was also obtained. The values of $[\mathrm{Htta}]_{\text {org, }}$ and $[\mathrm{TOPO}]_{\mathrm{org}, \mathrm{t}}$ thus obtained are introduced into Eq. (13) and the distribution ratio of copper(II) was calculated. The calculated value of distribution ratio agreed well with the experimentally obtained values in Fig. 3. Thus, the decrease in the distribution ratio of copper(II) in Fig. 3 was concluded to be due to the association of the Htta and TOPO in the organic phase which proceeded much more slowly than the complex formation, extraction of complex, and adduct formation of the copper(II) chelate. From the absorption of organic phase, the concentrations were calculated of both Htta and TOPO, which are not in the associated form and thus available for the solvent extraction of copper(II) and adduct formation with the extracted $\mathrm{Cu}(\mathrm{tta})_{2}$ given by Eq. (13). The distribution ratio of copper(II) after each agitation time was calculated by using the concentrations on the basis of Eq. (13). Table 2 gives the calculated and experimental values of the distribution ratio of copper(II) as a function of the two-phase agitation time. In these experiments, the concentration of TOPO is much larger than that of Htta and thus the TOPO concentration can approximately be regarded as constant but the $\mathrm{Htta}$ concentration decreases markedly by the association with TOPO. The calculated values in Table 2 agree with the experimental values.

In ordinary solvent extraction systems, the equilibrium is established within a very short time; usually a vigorous two-phase agitation for $3 \mathrm{~min}$ should be enough. Exceptions may be encountered when the hydrated metal ion is kinetically inert, such as $\mathrm{Be}^{2+}, \mathrm{Fe}^{3+}$, and $\mathrm{Cr}^{3+}$. When a gradual decrease in the distribution ratio of the metal occurs in a solvent extraction system, it should be due to a slow reaction between two organic materials in the system. When such a slow reaction is overlooked, the precise values of parameters in the solvent extraction system such as the equilibrium constants can not be obtained.

\section{References}

1. H. M. N. H. Irving, "Solvent Extraction Chemistry", Proceedings of the International Conference 1966, ed. D. Dyrssen, J.-O. Liljenzin, and J. Rydberg, pp. 91 - 110, North-Holland, Amsterdam, 1967; T. V. Healy, "Solvent Extraction Research", Proceedings of Fifth International Conference of Solvent Extraction Chemistry 1968, ed. A. S. Kertes and Y. Marcus, p. 257-280, Wiley-Interscience, New York, 1969.

2. T. Sekine, T. Saitou and H. Iga, Bull. Chem. Soc. Jpn., 56, 700 (1983).

3. W. D'Olieslager and L. Sannen, Solvent Extraction 1990, Proceedings of International Solvent Extraction Conference (ISEC '90), ed. T. Sekine, part A, p. 967, Elsevier, Amsterdam, 1992.

4. W. D'Olieslager and I. Drisque, Abstracts of Papers, 2International Conference of f-Elements, Helsinki, 1994, abstract PD11, p. 259.

5. T. Sekine, K. Takagi and Nguen T. K. Dung, Bull. Chem. Soc. Jpn., 66, 2558 (1993).

6. T. Sekine and N. Ito, Bunseki Kagaku, 33, E427 (1984).

7. A. Hokura and T. Sekine, Solvent Extraction Research and Development, Japan, 2, 102 (1995).

8. E. L. King and W. H. Reas, J. Am. Chem. Soc., 73, 1806 (1951).

9. T. Sekine, A. Hokura and I. Tanaka, Anal. Sci., in press.

10. M. R. Jaffe, D. P. Fay, M. Cefola and N. Sutin, J. Am. Chem. Soc., 93, 2878 (1971).

11. T. Sekine, Y. Hasegawa and N. Ihara, J. Inorg. Nucl. Chem., 35, 3968 (1973).

12. M. Nitsu, N. Iritani and T. Sekine, Bull. Chem. Soc. Jpn., 52, 1799 (1979).

13. T. Sekine and D. Dyrssen, J. Inorg. Nucl. Chem., 26, 1727 (1964). 